UCRL-ID-126990 Rev 2

\title{
National Ignition Facility SubSystem Design Requirements Optical Mounts SSDR 1.4.4
}

\author{
M. Richardson
}

October 6, 1996

This is an informal report intended primarily for internal or limited external dietribution. The opinione and conclusions atated are those of the author and may or my not be those of the Laboratory.

Work performed under the auppices of the U.S. Department of Energy by the Lawrence Livermore National Laboratory under Contract W-7405-Eng-48. 


\section{DISCLAIMER}

This document was prepared as an eccount of work sponsored by an agency of the United States Government. Neither the United Stutes Covernment nor the University of California nor any of their employees, makes any warranty, express or implied, or aseumes any legel liablity or respondibility for the accuracy, completenews, or usefulness of any information, sparatus, product, or proces dieclosed, or represents that its uee would not infininge privately owned rights. Reference herein to any specific commercial product, process, or service by trade name, trademark, manufacturer, or otherwise, does not nocesenrily constitute or imply its endoreement, recommendation, or favoring by the United States Covernment os the University of California. The views and opinions of nuthors expressed herein do not necessarily state or reflect those of the United States Government or the University of California, and shall not be used for advertibing or product endorsement purposes.

This report has been reproduced directly from the best availible copy.

Available to DOE and DOE contractors from the Office of Scientific and Technical Information

P.O. Box 62, Oak Ridge, IN 37831

Prices available from (615) 576-810, FTS 626-8401

Avallable to the public from the

National Technical Information Service

U.S. Department of Commerce

5285 Port Royal Rd.

Springfield, VA 22161 


\section{National Ignition Facility}

\section{Subsystem Design Requirements}

\section{Optical Mounts \\ SSDR 1.4.4}

\section{Revision 2}

October 6, 1996

Prepared by:

M. Richardson, Optomechanical Systems Lead Engineer

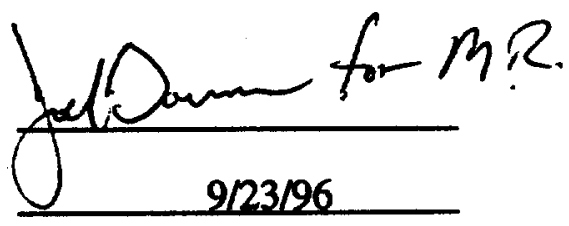

Reviewed:

J. Bowers, Beam Transport System Engineer

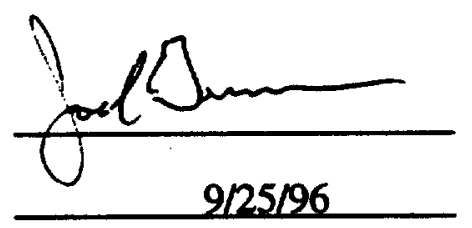

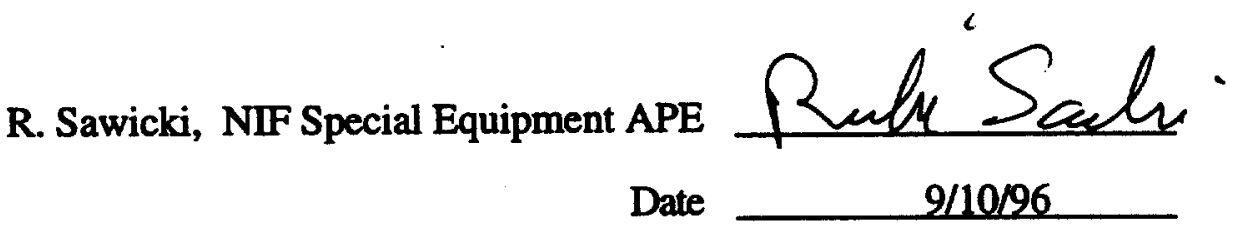

Engineering Review Board Approval:

S. A. Kumpan, NIF Project Engineer

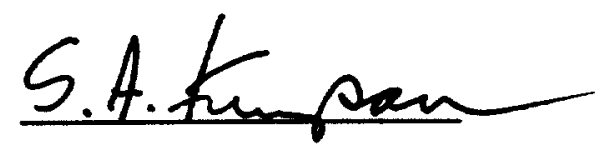

Date $10 / 6 / 96$ 


\section{Table of Contents}

\section{Paragraph}

1.0

2.0

2.1

2.1.1

2.1.2

2.1.3

2.2

2.2.1

2.2 .2

2.3

2.4

3.0

3.1

3.1.1

3.1 .2

3.1.3

3.1.3.1

3.1 .4

3.1.4.01

3.1.4.02

3.1.4.03

3.1.4.04

3.1.4.05

3.1.4.07

3.1.4.09

3.2

3.2.1

3.2.1.01

3.2.1.01.01

3.2.1.01.02

3.2.1.01.03

3.2.1.01.04

3.2.1.01.05

3.2.1.01.06

3.2.1.03

3.2.1.03.01

3.2.1.03.02

3.2.1.03.05

3.2.1.04

3.2.1.04.01

3.2.1.04.02

3.2.1.04.03

3.2.1.04.04

3.2.1.04.05

3.2.1.04.06

3.2.1.05

3.2.1.05.01

3.2.1.05.02

3.2.1.05.03
Title

Scope

Applicable Documents

Applicable NIF Documents

Applicable NIF Project Documents

Applicable NIF Drawings

Interface Control Documents

Applicable US Government Orders, Codes, and Standards

DOE Orders

Other Government Regulations

Applicable National Consensus Codes and Standards

Applicable LLNL Standards

Subsystem Characteristics and Verification

Subsystem Definition

Subsystem Description

Subsystem Functions

Subsystem Diagrams

Subsystem Operating Modes

Subsystem Interfaces

LM1 Optical Mount Interfaces

LM2 Optical Mount Interfaces

Polarizer/LM3 Optical Mount Interfaces

Spatial Filter Lens Mounts Interfaces

Injection Mirror Mount Interfaces

Switchyard Mirror Mount Interfaces

Target Area Mirror Mounts

Requirements and Verification

Performance Characteristics

Spatial Filters

Spatial Filter Lens Translational Stability

Spatial Filter Lens Rotational Stability

Spatial Filter Lens Position Accuracy

Spatial Filter Lens Rotational Position accuracy

Stress Induced Birefringence

Lens Maximum Principle Stress

Injection Mirror

Injection Mirror Translational Stability

Injection Mirror Rotational Stability

Lens Stress Induced Birefringence

Cavity Mirror Mount Assemblies

LM1/LM2 Mounted Wavefront Distortion

Alignment Positioner Accuracy

Alignment Positioner Resolution

Alignment Positioner Range

Mirror Angular Stability

LM1/LM2 Mirror Position Accuracy

Polarizer/LM3 Mount Assemblies

Polarizer/LM3 Mounted Wavefront Distortion

Alignment Positioner Accuracy

Alignment Positioner Resolution 


\section{Table of Contents}

Paragraph

3.2.1.05.04

3.2.1.05.05

3.2.1.05.06

3.2.1.06

3.2.1.06.01

3.2.1.06.02

3.2.1.06.03

3.2.1.06.04

3.2.1.06.05

3.2.1.06.06

3.2.1.08

3.2 .2

3.2.2.1

3.2.2.1.1

3.2.2.1.2

3.2.2.2

3.2.2.2.1

3.2.2.2.2

3.2.3

3.2.3.1

3.2.3.2

3.2.3.3

3.2.3.4

3.2.3.5

3.2.3.6

3.2 .4

3.2.4.1

3.2.4.2

3.2.4.3

3.3

3.3 .01

3.3.01.1

3.3.02

3.3.02.1

3.3.03

3.3.04

3.3 .05

3.3.06

3.3.07

3.3.08

3.3 .09

3.4

3.4.1

3.4 .2

3.4 .3

4.0

4.1

6.0
Title

Alignment Positioner Range

Polarizer/LM3 Angular Stability

Polarizer/LM3 Mirror Position Accuracy

Beam Transport Turning Mirror Mount Assemblies

Beam Transport Turning Mirror Mounted Wavefront Distortion

Alignment Positioner Accuracy

Alignment Positioner Resolution

Alignment Positioner Range

Mirror Angular Stability

Mirror Position Accuracy

Number of Beams

Physical Characteristics

General Arrangement

Optomechanical Subsystem Architecture

General Arrangement Drawings

Optomechanical Subsystem General Configuration

Cassette Assemblies

Mirror Assemblies

Reliability, Availability, Maintainability

Lifetime

Replaceability

Inherent Availability

Reliability

Maintainability

Recovery From abnormal events

Environmental

Ambient Temperature/Humidity

Ambient Cleanliness

Ambient Vibration Environment

Design and Construction

Safety

Fail-Safe Design

Cleanliness

Internal Cleanliness

Future Modifications and Upgrades

Decommissioning

Human Factors

Interchangeability

Documentation and Records

Design Processes

Supervisory Control

Logistics

Spare Equipment

Maintenance Equipment

Bottom-Access Maintenance

QA Provisions

Q-Level Assigned

Revision Record 
1.0 Scope

This SSDR establishes the performance, design, development, and test requirements for NIF Beam Transport Optomechanical Subsystems. Optomechanical Subsystems includes the mounts for the beam transport mirrors, LM1 - LM8, the polarizer mount, and the spatial filter lens mounts.

\subsection{Applicable Documents}

This section lists NIF Project Documents, DOE and other government orders, codes, and standards, and national consensus standards which are applicable to the Beam Transport Optomechanical Subsystem. Applicable LLNL standards are also being considered contingent upon the decision of final site selection.

\subsection{Applicable NIF Documents}

The following NIF Project Documents apply to the Beam Transport Optomechanical'Subsystem as specifically referenced in later sections.

\subsubsection{Applicable NIF Project Documents}

National Ignition Facility Functional Requirements and Primary Criteria, Revision 1.4, L-15983-3, February, 1996

National Ignition Facility System Design Requirements, Laser System SDR002, Revision A, NIF-LLNL-96-228, L-21707-01

"Proposed Metrication Policy for NIF," memo from R. Sawicki, NIF-LLNL-96-038, L-21248-01, 21 January, 1996

NIF Grounding Plan, NIF-LLNL-94-211, L-17346-1

NIF-LLNL-93-044/L-15958-1, National Ignition Facility Quality Assurance Program Plan, November 1993

\subsubsection{Applicable NIF Drawings}

The following NIF Project drawings apply as specified in sections 3.2 to 3.6. The specified revision applies.

AAA-96-104905-0A, Layout, Beam Transport Configuration

AAA-96-100596-0B, LTAB NIF Optics Main Laser Optic System, 7/19/96

Parsons Drawing No CFG-201, "LTAB, Floor Plan at Level -0"', 4/16/96

\subsubsection{Interface Control Documents}

Interface requirements between WBS level 1.4.4 and other subsystems are controlled through separate Interface Control Documents (ICDs).

\subsection{Applicable US Government Orders, Codes, and Standards}

\subsubsection{DOE Orders}

- 5700.6C - Quality Assurance

- 420.1 - Facility Safety

- 440.1 - Worker Protection Management for DOE Federal and Contractor Employees

- 5400.1 General Environmental Protection Program

\subsubsection{Other Government Regulations}

- MIL-STD 1246C - Product Cleanliness for Levels and Contamination Control Program

\subsection{Applicable National Consensus Codes and Standards}


- DOE-STD-1020-94 Natural Phenomena Hazards Design and Evaluation Criteria for DOE Facilities

- ANSUASME B1.1 Standard for bolt threads

- ASTM A307 Standard Specification for Carbon Steel Bolts an Studs, 60,000 psi Tensile Strength

- ASTM A325 Standard Specification for High Strength Bolts for Structural Steel Joints

- ASTM A36 Standard Specification for Structural Steel

- ASTM A449 Standard Specification for Quenched and Tempered Steel Bolts and Studs

- ASTM A490 Standard Specification for Heat-Treated Steel Structural Bolts, 150 ksi Minimum Tensile Strength

- ASTM A6 Chemical analysis for structural steel

- ASTM A751, F606 -testing methods for bolts and studs

- ASTM D 3951 (packaging of bolts and studs)

- ASTM F568, A563 Appurtenances for structural steel (nuts and bolts)

\subsection{Applicable LLNL Standards}

Pending final site selection, the following LLNL standards generally apply to NIF, and are assumed to apply to the optomechanical subsystem until determined otherwise.

LLNL M-012 Rev 7, Feb 1993, "Design Safety Standards -Mechanical Engineering"

LLNL M-010, March 1989, "Health and Safety Manual"

LLNL M-010 "Hazards Control Manual"

LLNL M-256 "Mechanical Engineering Design Practice"

LLNL "Mechanical Engineering Policy Procedures Manual"

\subsection{Subsystem Characteristics and Verification}

\subsection{Subsystem Definition}

The Beam Transport Optomechanical Subsystem provides the optical mounts for all full aperture optical elements, excluding the amplifiers, the pockels cells, and FOA's in each of the 192 beam lines. Each mount incorporates the articulation required by the alignment system to point the beams to Target Chamber center. The optical elements that are mounted in this subsystem include the cavity mirrors, polarizer, transport mirrors, and the spatial filter lenses.

\subsubsection{Subsystem Description}

The Optomechanical Subsystem optical mounts are packaged into cassettes to facilitate the bottom load maintenance concept to be utilized in the laser bays. The cavity mirrors and spatial filter lenses will be assembled into 4 high cassettes. The polarizer and laser mirror 3, LM3, will be assembled into cassettes in pairs.In the switchyard, mirror assemblies LM4 and LM5 will be mounted to the switchyard support structure. Target Area mirror assemblies, LM6, LM7, and LM8 will be mounted in 1 X 2 and 2 X 2 arrays on the Target Area support structure.

\subsubsection{Subsystem Functions}

The cavity mirror mount assemblies, located at both ends of the laser cavity, provide support and remote alignment of the cavity mirrors. These mirrors reflect the beam back and forth to accomplish multi-pass amplification. The transport turning-mirror mounts provide support and alignment of the mirrors that transport the beam from the laser cavity to the target. The NIF polarizer mount assembly provides support and remote alignment of the polarizer plate to Brewster's angle. The polarizer plate works in conjunction with the Pockels cell to switch the beam out of the laser cavity after four-pass amplification.

Cavity Mirror Mount Assemblies

- Provide support and remote alignment of the cavity mirrors.

- These mirrors reflect the beam back and forth to accomplish multi-pass amplification. 
Transport Turning Mirror Mounts

- Provide support and remote alignment of the transport mirrors.

- The mirrors transport the beam from the laser cavity to the target.

Polarizer Mount Assembly

- Provides support and remote alignment of the polarizer plate to Brewster's angle.

- The polarizer plate works in conjunction with the Pockels Cell to switch the beam out of the laser cavity after four-pass amplification.

\subsubsection{Subsystem Diagrams}

\subsubsection{Subsystem Operating Modes}

The operating mode of the optical mounts is discussed in the Beam Control and Diagnostics Subsystems, WBS 1.7.1.

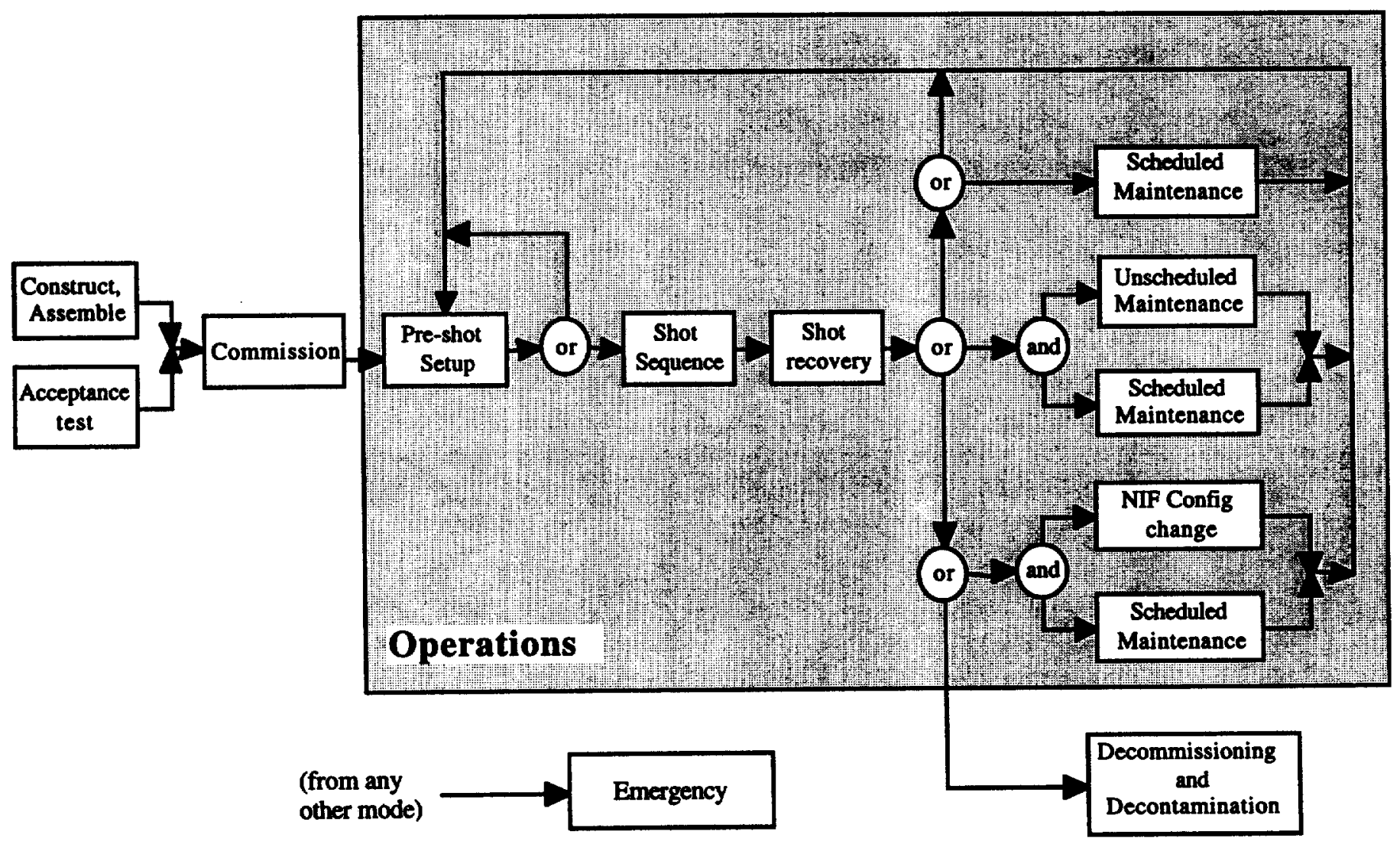

Figure 3.1.3.1-1 NIF operating modes.

\subsubsection{Subsystem Interfaces}

\subsubsection{LM1 Optical Mount Interfaces}

The LM1 optical mount interfaces include:

Wave Front Control Systems - Adaptive Optics (WBS 1.7.3.1) 
The LM1 optical mount locates and points the deformable mirror.

Laser Alignment Systems (WBS 1.7.1)

Laser alignment systems controls the stepper motor driven actuators to provide tip/tilt control of the mirror mount and two alignment light sources are located behind the deformable mirror.

\section{Laser Bay Support Structures (WBS 1.4.3.2)}

The cassette holding an array of LM1 optical mounts is mounted in the deformable mirror support structure on kinematic supports.

\section{Optics Handling Equipment (WBS 1.1.1.3.2)}

The LM1 cassette interfaces with the optics maintenance/transfer cart.

\section{Optics Assembly Building (WBS 1.2.2.3)}

The LM1 cassette and mounts interface with the assembly and alignment workstations in the Optics Assembly Building.

\subsubsection{LM2 Optical Mount Interfaces}

The LM2 optical mount interfaces include:

Mirrors (WBS 1.6.3)

The optical element is held in the mount.

Laser Alignment Systems (WBS 1.7.1)

Laser alignment systems controls the stepper motor driven actuators to provide tip/tilt control of the mirror mount.

Laser Bay Support Structures (WBS 1.4.3.2)

The cassette holding an array of LM2 optical mounts is mounted in the periscope support structure on kinematic supports.

\section{Laser Beam Diagnostics (WBS 1.7.2)}

The mid-chain diagnostic is located behind LM2. This requires that full aperture clearance be maintained through LM2 to the diagnostic.

Optics Handling Equipment (WBS 1.1.1.3.2)

The LM2 cassette interfaces with the optics maintenance/transfer cart.

Optics Assembly Building (WBS 1.2.2.3)

The LM2 cassette and mounts interface with the assembly and alignment workstations in the Optics Assembly Building.

\subsubsection{Polarizer/LM3 Optical Mount Interfaces}

The Polarizer/LM3 optical mount interfaces include:

Mirrors (WBS 1.6.3)

Polarizers(WBS 1.6.4)

The optical elements are held in the mounts.

\section{Laser Alienment Systems (WBS 1.7.1)}

Laser alignment systems controls the stepper motor-driven actuators to provide tip/tilt control of the LM3 mirror and polarizer mounts. There is an alignment light source located behind LM3 requiring a partial clear aperture.

\section{Laser Bay Support Structures (WBS 1,4.3.2)}


The cassette holding a polarizer and LM3 optical mounts is mounted in the periscope support structure on kinematic supports.

Optics Handling Equipment (WBS 1.1.1.3.2)

The LM3/polarizer cassette interfaces with the optics maintenance/transfer cart.

Optics Assembly Building (WBS 1.2.2.3)

The polarizer/LM3 cassette and mounts interface with the assembly and alignment workstations in the Optics Assembly Building.

\subsubsection{Spatial Filter Lens Mounts Interfaces}

The spatial filter lens mount interfaces include:

\section{Lenses (WSB 1.6.2)}

The optical elements are held in the mounts.

Spatial Filter Vacuum Vessels (WBS1.4.1)

The lens mounts mount to the ends of the vacuum vessels providing the vacuum seal, locating the lens in the beam line.

Interstage Beam Enclosures (WBS 1,4.1)

Access through the interstage enclosures will be required for the maintenance/transfer cart to remove and replace spatial filter lenses.

\section{Optics Handling Equipment (WBS 1.1.1.3.2)}

The spatial filter lens cassette interfaces with the optics maintenance/transfer cart.

Optics Assembly Building (WBS 1.2.2.3)

The spatial filter lens cassette and mounts interface with the assembly and alignment workstations in the Optics Assembly Building.

\subsubsection{Injection Mirror Mount Interfaces}

The injection mirror mount have the following interfaces:

Mirrors (WBS 1.6.3)

The optical elements are held in the mounts.

\section{Beam Transport Vacuum Enclosures (WBS 1.4.1)}

A 4 high array of injection mirrors mounted in cassettes are inserted through the top of the spatial filter vacuum enclosures.

TSF Tower Optic Assembly (WBS 1.7.1.2)

The injection mirror mount is mounted and aligned to the TSF tower optic assembly.

Optics Assembly Building (WBS 1.2.2.3)

The injection mirror mount cassette and mounts interface with the assembly and alignment workstations in the Optics Assembly Building.

\subsubsection{Switchyard Mirror Mount Interfaces}

The switchyard mirror mounts have the following interfaces:

Mirrors (WBS 1.6.3)

The optical elements are held in the mounts. 


\section{Support Structures (WBS 1.4.3)}

The switchyard mirrors, LM4 and LM5, are mounted on the switchyard support structures.

Switchyard Beam Enclosures (WBS 1.4.1)

The switchyard beam enclosure mount to the mirror mount enclosure.

Optics Handling Equipment (WBS 1.1.1.3.2)

The switchyard mirror mount interfaces with the optics maintenance/transfer cart.

Optics Assembly Building (WBS 1.2.2.3)

The switchyard mirror mounts interface with the assembly and alignment workstations in the Optics Assembly Building.

\subsubsection{Target Area Mirror Mounts}

Target area mirror mounts have the following interfaces:

\section{Mirrors (WBS 1.6.3)}

The optical elements are held in the mounts.

\section{Target area structures (WBS 1.8.4)}

The target area mirror mounts interface with the target area mirror support structures and the target area beam tubes.

\section{Beam Diagnostics (WBS 1.7.2)}

Back scatter diagnostics are located behind LM8, requiring clearance for a full aperture beam through the mirror.

\section{Optics Handling Equipment (WBS 1.1.1.3.2)}

The target area mirror mount interfaces with the optics maintenance/transfer cart.

\section{Optics Assembly Building (WBS 1.2.2.3)}

The target area mirror mount interface with the assembly and alignment workstations in the Optics Assembly Building.

\subsection{Requirements and Verification}

The following sections define the minimum requirements which must be met by the Beam Transport Optomechanical Subsystem, related to performance, physical characteristics, etc.

\subsubsection{Performance Characteristics}

The $\mathrm{X}, \mathrm{Y}$, and $\mathrm{Z}$ directions for stability and position requirements are defined in thedrawings listed in section 2.1.2.

\subsubsection{Spatial Filters}

\subsection{Spatial Filter Lens Translational Stability}

Spatial filter lens,SF1 \& SF2, translational stability shall be: $\left(\Delta x^{\wedge} 2+\Delta y^{\wedge} 2\right)^{\wedge} 0.5 \leq 6 \mu \mathrm{m}$ for the 2 hours after alignment and during a shot. Spatial filter lens,SF3 \& SF4, translational stability shall be: $\left(\Delta x^{\wedge} 2+\Delta y^{\wedge} 2\right)^{\wedge} 0.5 \leq 7 \mu \mathrm{m}$ for the 2 hours after alignment and before a shot, with SF4 translating $\leq 100 \mu \mathrm{m}$ in the $\mathrm{Z}$ direction in the same period.

\subsection{Spatial Filter Lens Rotational Stability}

Spatial filter lens, SF1 - SF3, rotational stability shall be: $\left(\Delta \mathrm{Qx}^{\wedge} 2+\Delta \mathrm{Q}^{\wedge} 2\right)^{\wedge} 0.5 \leq 200 \mu \mathrm{rad}$ over the $2 \mathrm{hr}$ period after alignment and before a shot. 
Spatial filter lens, SF4, rotational stability shall be: $\left(\Delta Q \mathrm{Qx}^{\wedge} 2+\Delta \mathrm{Qy}^{\wedge} 2\right)^{\wedge} 0.5 \leq 0.7 \mu \mathrm{rad}$ over the $2 \mathrm{hr}$ period after alignment and before a shot.

\subsection{Spatial Filter Lens Position Accuracy}

All spatial filter lens, SF1-SF4, position accuracy shall be: $\left(\Delta x^{\wedge} 2+\Delta y^{\wedge} 2\right)^{\wedge} 0.5 \leq 1 \mathrm{~mm}$.

Spatial filter lens, SF1 \& SF2, position accuracy shall be: $\Delta z \leq \pm 1 \mathrm{~mm}$.

Spatial filter lens, SF3 \& SF4, position accuracy shall be: $\Delta z \leq \pm 3 \mathrm{~mm}$.

\subsection{Spatial Filter Lens Rotational Position Accuracy}

SF1 - SF3 Spatial filter lens rotational position accuracy shall be: $\left(\Delta Q x^{\wedge} 2+\Delta Q y^{\wedge} 2\right)^{\wedge} 0.5 \leq 0.1^{\circ}$.

SF4 Spatial filter lens transverse rotational position accuracy shall be consistent with the requirements of the wavefront diagnostic subsystem.

All spatial filter lens, SF1-SF4, rotational position accuracy shall be: $\Delta \mathrm{Qz} \leq \pm 1 \mathrm{mrad}$.

\subsection{Stress Induced Birefringence}

The stress induced befringence shall be $\leq \mathrm{TBD}$.

\subsection{Lens Maximum Principle Stress}

The spatial filter lens shall be mountedso that the maximum principle stresses under vacuum loadare $\leq 700 \mathrm{psi}$ new and 800 psi after refinishing.

\subsubsection{Injection Mirror}

\subsection{Injection Mirror Translational Stability}

The Transport spatial filter beam-injection mirror "LM0" translational stability shall be: $\Delta x, \Delta y, \Delta z \leq 100 \mu \mathrm{m}$.

\subsection{Injection Mirror Rotational Stability}

Transport spatial filter beam-injection mirror "LMO" rotational stability shall be:

$\left(\Delta Q \mathrm{x}^{\wedge} 2+\Delta \mathrm{Q} \mathrm{y}^{\wedge} 2\right)^{\wedge} 0.5 \leq 0.7 \mu \mathrm{rad}$.

\subsubsection{Cavity Mirror Mount Assemblies}

\subsection{LM1/LM2 Mounted Wavefront Distortion}

Mounted wavefront distortion for LM1 and LM2 shall be TBD.

\subsection{Alignment Positioner Linearity}

Alignment positionershall be linear within $3 \%$ for short travel distances, $\sim 100$ motor steps, and over the full range of travel.

\subsection{Alignment Positioner Resolution}

Alignment positioner resolution shall be: $\leq 0.1-\mu$ rad incremental adjustment.

\subsection{Alignment Positioner Range}

Alignment positioner range shall be: $\geq \pm 5 \mathrm{mrad}$.

\subsection{Mirror Angular Stability}

LM1 mirror angular stability shall be: $\leq 0.6 \mu \mathrm{rad}$ over $2 \mathrm{hr}$.

LM2 mirror angular stability shall be: $\leq 0.7 \mu \mathrm{rad}$ over $2 \mathrm{hr}$.

\subsection{LM1/LM2 Mirror Position Accuracy}


Installation position accuracy shall be: $\left(\Delta x^{\wedge} 2+\Delta y^{\wedge} 2\right)^{\wedge} 0.5 \leq 3.0 \mathrm{~mm}$.

\subsubsection{Polarizer/LM3 Mount Assemblies}

3.2.1.05.01 Polarizer/LM3 Mounted Wavefront Distortion

Mounted wavefront distortion for the Polarizer and LM3 shall be TBD.

\subsection{Alignment PositionerLinearity}

Alignment positioner shall be linear within $3 \%$ for short travel distances, $\sim 100$ motor steps, and over the full range of travel.

\subsection{Alignment Positioner Resolution}

Alignment positioner resolution shall be: $\leq 0.1 \mu \mathrm{rad}$ incremental adjustment.

\subsection{Alignment Positioner Range}

Alignment positioner range shall be: $\geq \pm 5 \mathrm{mrad}$.

\subsection{Polarizer/LM3 Angular Stability}

Polarizer/LM3 angular stability shall be: $\leq 0.6 \mu \mathrm{rad}$ over $2 \mathrm{hr}$.

\subsection{Polarizer/LM3 Mirror Position Accuracy}

Installation position accuracy shall be: $\left(\Delta x^{\wedge} 2+\Delta y^{\wedge} 2\right)^{\wedge} 0.5 \leq 3.0 \mathrm{~mm}$.

Installation position accuracy shall be: $\Delta \mathrm{z} \leq 3.0 \mathrm{~mm}$.

\subsubsection{Beam Transport Turning Mirror Mount Assemblies}

3.2.1.06.01 Beam Transport Turning Mirror Mounted Wavefront Distortion Mounted wavefront distortion for the transport mirrors shall be TBD.

3.2.1.06.02 Alignment Positioner Linearity

Alignment positioner shall be linear within $3 \%$ for short travel distances, $\sim 100$ motor steps, and over the full range of travel.

\subsection{Alignment Positioner Resolution}

Alignment positioner resolution shall be: $\leq 0.1-\mu \mathrm{rad}$ incremental adjustment.

\subsection{Alignment Positioner Range}

Alignment positioner range shall be: $\geq \pm 7.5 \mathrm{mrad}$.

\subsection{Mirror Angular Stability}

Mirror angular stability shall be: $\leq 0.7 \mu \mathrm{rad}$ over $2 \mathrm{hr}$.

\subsection{Mirror Position Accuracy}

Installation position accuracy shall be: $\left(\Delta x^{\wedge} 2+\Delta y^{\wedge} 2\right)^{\wedge} 0.5 \leq \operatorname{TBD}(1 \mathrm{~mm})$.

Installation position accuracy shall be: $\Delta \mathrm{z} \leq \operatorname{TBD}(1 \mathrm{~mm})$.

\subsubsection{Number of Beams}

The optomechanical subsystem shall be configured to process 192 simultaneous beams.

\subsubsection{Physical Characteristics}




\subsubsection{General Arrangement}

\subsection{Optomechanical Subsystem Architecture}

The optomechanical subsystem shall incorporate the following basic architecture:

- beam control and diagnostic component

LM5

LM6,7

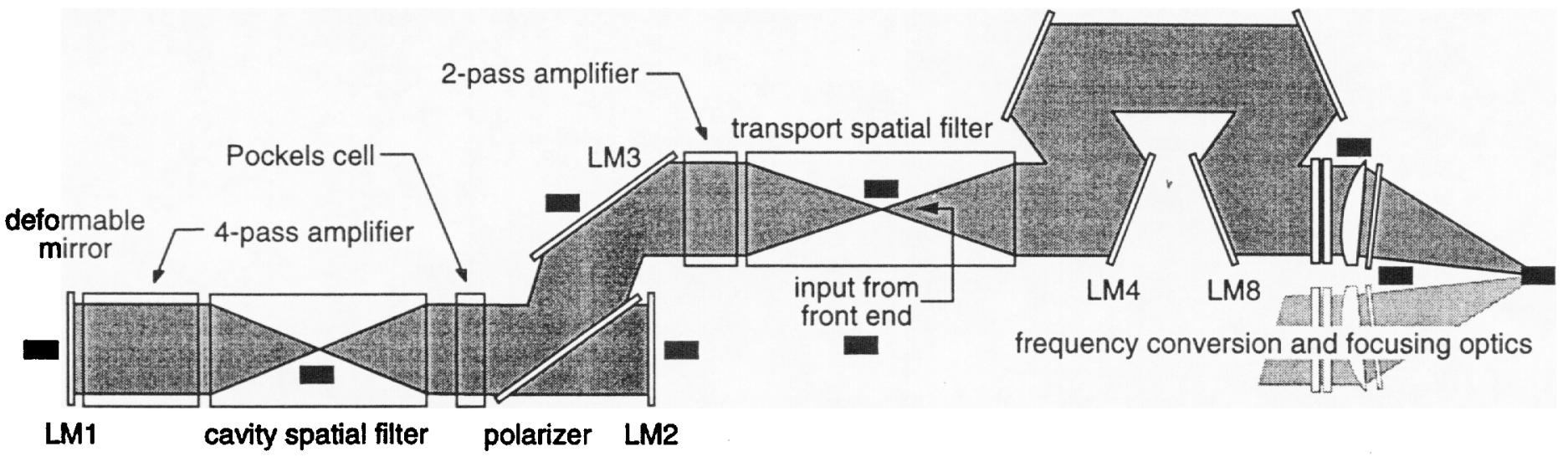

Figure 3.2.2.1.1: Optomechanical Mirror Locations.

\subsection{General Arrangement Drawings}

The optomechanical subsystem shall conform to the drawings indicated in section 2.1 .2 which specify the general arrangement.

\subsubsection{Optomechanical Subsystem General Configuration}

\subsection{Cassette Assemblies}

The cavity mirrors and spatial filter lenses should be assembled in $4 \times 1$ cassettes to conform with the $4 \times 2$ laser bundle configuration.

The polarizer and laser mirror 3 (LM3) shall be assembled in $2 \times 1$ cassettes to conform with the $4 \times 2$ laser bundle configuration.

\subsection{Mirror Assemblies}

Laser mirrors 4 through 8 and the gas box windows shall be configured in $2 \times 2,2 \times 1$ or $1 \times 2$ arrays in as required to transport the $2 \times 2$ laser "quad" beams to target.

\subsubsection{Reliability, Availability, Maintainability}

\subsubsection{Lifetime}

The optomechanical subsystem shall be designed for a 30 year lifetime.

\subsubsection{Replaceability}

Any portion of the optomechanical subsystem which cannot reasonably be designed for 30-year lifetime shall be designed to be replaced or repaired at reasonable cost in a timely manner consistent with the overall availability of the optomechanical subsystem as stated in 3.2.3.3 and 3.2.3.5. The following components are line replaceable units:

1) LM1 cassette

2) LM2 cassette

3) Polarizer/LM3 cassette

4) SF1/SF2 cassette 
5) $\mathrm{SF} 3$ cassette

6) SF4 cassette

All components with the same part number shall be interchangeable.

\subsubsection{Inherent Availability}

The optomechanical subsystem shall have a shot availability of at least $99.71 \%$. The system is unavailable when it is undergoing unplanned maintenance. Unplanned maintenance includes failure detection and active repair as well as logistic and administrative downtimes.

\subsubsection{Reliability}

The optomechanical subsystem shall have an overall reliability of $98.67 \%$. Reliability is defined as the probability of meeting the minimum requirements of the experiment for each no-yield shot as stated in SDR2:3.2.3.4.

\subsubsection{Maintainability}

The optomechanical subsystem shall have a scheduled maintenance plan that fits within an overall annual plant goal of 69 days. The unplanned maintenance goal is 18 hours per year. Opportunistic maintenance activities are performed between shots and during other system downtimes.

\subsubsection{Recovery From Abnormal Events}

The time required for the optomechanical subsystem to recover from any abnormal event shall be less than the maximum times cited below, as a function of the expected yearly frequency of occurrence of the event.

\begin{tabular}{cc} 
Expected Frequency of Occurrence Per Year. $F$ & Maximum Recovery Time \\
\hline$F \geq 1$ & 24 hours \\
$1>F>1 E-2$ & 1 week \\
$1 E-2>F \geq 5 E-4$ & 3 months
\end{tabular}

Probabilities listed in DOE-STD-1020-94 shall be used for natural phenomena

\subsubsection{Environmental}

Maintenance plans for all optomechanical subsystems shall be capable of supporting a shot rate of one shot every eight hours and the plan shall not preclude shot rates of one shot every four hours.

\subsubsection{Ambient Temperature/Humidity}

All optomechanical subsystem components within the Laser and Target Building shall meet all requirements when operated at a temperature of $20^{\circ} \mathrm{C} \pm 0.3^{\circ} \mathrm{C}$, a relative humidity of $30 \%$ to $60 \%$, and a pressure equal to ambient atmospheric pressure $\pm \mathrm{TBD} \mathrm{cm}$ water (to accommodate positive/negative air systems). Any components normally operated outside the LTAB Building shall meet all requirements when operated between $-4.4^{\circ} \mathrm{C}$ (dry bulb, winter) and $20.6^{\circ} \mathrm{C}$ (wet bulb, summer) or $37.8^{\circ} \mathrm{C}$ (dry bulb, summer), and local atmospheric pressure.

\subsubsection{Ambient Cleanliness}

The optomechanical subsystem shall meet all requirements when operated within the NIF LTAB. The ambient cleanliness levels in pertinent areas of the LTAB are as follows:

Area Ambient Cleanliness Class

Laser Bay 100,000

Switch yard 100,000

Target Bay 100,000

\subsubsection{Ambient Vibration Environment}

The optomechanical subsystem shall meet all requirements, while being exposed to ambient random vibration of $10^{-10} \mathrm{~g}^{2} / \mathrm{Hz}$, from 1 to $200 \mathrm{~Hz}$, applied at the special-equipment mounting surface of the foundation of the Laser or Target Area building. 


\subsection{Design and Construction}

The site for NIF has not yet been selected. The present design is therefore non-site-specific. For the purpose of Title I design of the Target Experimental System, it shall be assumed that NIF will be constructed at a site with the general infrastructure as available at candidate sites. Specific environmental assumptions are listed in the following sections.

\subsubsection{Safety}

The optomechanical subsystem shall be designed, constructed, and operated as part of the NIF such that it is a low-hazard, radiological component of the NIF. Compliance with this classification shall be verified through a Preliminary Hazard Analysis assessment of bounding accidents involving those radionuclides presenting the most significant hazards (see DOE Order 5481.1B, Safety Analysis Review System). Administrative controls shall be established prior to KD3 to ensure that inventory limits for a radiological low-hazard, non-nuclear facility are not exceeded.

Unless otherwise specified herein, all elements of the optomechanical subsystem shall meet the requirements of the LLNL Mechanical Engineering Design Safety Standards, Electrical Engineering Design Standards, and Laser safety standards.

\subsubsection{Fail-Safe Design}

Wherever reasonably possible, optomechanical subsystem shall be designed to fail safe upon inadvertent loss of power or other failure. A failure modes and effects (FMEA) analysis shall be conducted to ensure that critical failure modes are obviated or mitigated.

\subsubsection{Cleanliness}

\subsubsection{Internal Cleanliness}

The internal optiomechanical assemblies shall be precision cleaned and assembled in a Class 100 clean room environment, per FED-STD-209D. During operation of the laser, the optical elements of the laser shall be maintained at a surface cleanliness level as defined by MIL-STD-1246C - Level 50. Permissible cleanliness degradation shall be budgeted across the assembly, measurement, transport, storage, installation and operation phases of laser construction. This budget is described in the document entitled, "Cleanliness Degradation Budgeting for the NIF Laser." The NVR (Non Volatile Residue) level for optical components shall conform to Level A of MIL-STD-1246C or $1 \mathrm{mg} \mathrm{m}^{-2}$.

\subsubsection{Future Modifications and Upgrades}

As a design goal, the optomechanical subsystem shall provide for future reconfiguration and modification at minimum cost and with minimum effect on the overall operation of the facility as per section 3.2.1.22.2. of SDR 2.

\subsubsection{Decommissioning}

The optomechanical subsystem shall include considerations to allow cost effective future decommissioning of all structures and equipment.

\subsubsection{Human Factors}

The optomechanical subsystem shall be designed in an ergonomic fashion to ensure that human reliability during operation and maintenance is sustained at a level consistent with meeting overall availability and reliability objectives. Consistency in human interfaces should be maintained.

\subsubsection{Interchangeability}

Interchangeability of components shall be preserved as much as practical. Equipment with the same function and physical characteristics shall be interchangeable. 


\subsubsection{Documentation and Records}

The optomechanical subsystem shall provide sufficient documentation to comply with the NIF Quality Assurance Plan, and DOE Order 5700.6C, Quality Assurance, Criterion-4 Documents and Records, which states:

"Documents shall be prepared, reviewed, approved, issued, used and revised to proscribe processes, specify requirements or establish design. Records shall be specified, prepared, reviewed approved and maintained."

Examples of documents that should be controlled include drawings, data files, calculations, specifications, computer codes, purchase orders, vendor supplied documents, procedures, work records and data sheets and test records. Revisions should be reviewed by the organizations that originally prepared and approved the documents. Controlled documents should be distributed to those doing the work.

\subsubsection{Design Processes}

Design shall be carried out using sound engineering principles and appropriate standards. Design work including changes shall incorporate applicable requirements and design bases. Interfaces shall be identified and controlled. The adequacy of design products shall be verified or validated by qualified individuals other than those who did the work. Verification and Validation work shall be completed before approval and implementation of the design.

\subsubsection{Supervisory Control}

The optomechanical subsystem shall provide for positioning control by the automatic alignment system. The control system shall be designed to provide control functions required for normal operation and maintenence.

\subsection{Logistics}

\subsubsection{Spare Equipment}

As a part of the design/construction project, the optomechanical subsystem shall provide an initial complement of spare parts as required to activate the system.

\subsubsection{Maintenance Equipment}

As a part of the design/construction project, the optomechanical subsystem shall provide all equipment required to inspect, service, and maintain itself to meet the maintainability and availability requirements in \$3.2.3.

Maintenance equipment shall include all handling fixtures, lifting equipment, cleaning equipment and other special tools not otherwise available within NIF, that are necessary to perform any planned (scheduled or unscheduled) maintenance activity.

\subsubsection{Bottom-Access Maintenance}

As a design goal, all components within the laser bays should be accessed for maintenance from below.

\subsection{QA Provisions}

Quality Assurance for this subsystem will be determined by verification methods identified in $\$ 3$, in combination with the identified Quality Level for individual components.

\subsection{Q-Level Assigned}

\begin{tabular}{|c|c|c|c|c|c|}
\hline \multirow[t]{2}{*}{$\begin{array}{l}\text { WBS } \\
\text { element } \\
\text { number }\end{array}$} & \multirow[t]{2}{*}{ WBS element title } & \multicolumn{3}{|c|}{$\begin{array}{l}\text { Assigned } \\
\text { Q-level }\end{array}$} & \multirow[t]{2}{*}{ Why not Q-level 3 ? } \\
\hline & & $\mathbf{1}$ & 2 & 3 & \\
\hline 1.4.4.1 & Switchyard Optical Mounts & & & $\sqrt{ }$ & \\
\hline 1.4 .4 .2 & Periscope Mounts & & & $\sqrt{ }$ & \\
\hline 1.4 .4 .3 & Spatial Filter Optical Hardware & & & $\sqrt{ }$ & \\
\hline$\overline{1.4 .4 .4}$ & Optical Alignment Hardware & & & $\sqrt{ }$ & \\
\hline
\end{tabular}




\subsection{Revision Record}

\begin{tabular}{|l|l|l|l|l|}
\hline Rev & Date & ECR\# & By & Description of/Reason for Change \\
\hline 0 & CDR & n/a & & \\
\hline A & $6 / 4 / 96$ & n/a & Richardson & inital Title I issue \\
\hline B & $10 / 6 / 96$ & 61 & Richardson & final Title I update, many miscellaneous changes, TBDs eliminated \\
\hline
\end{tabular}




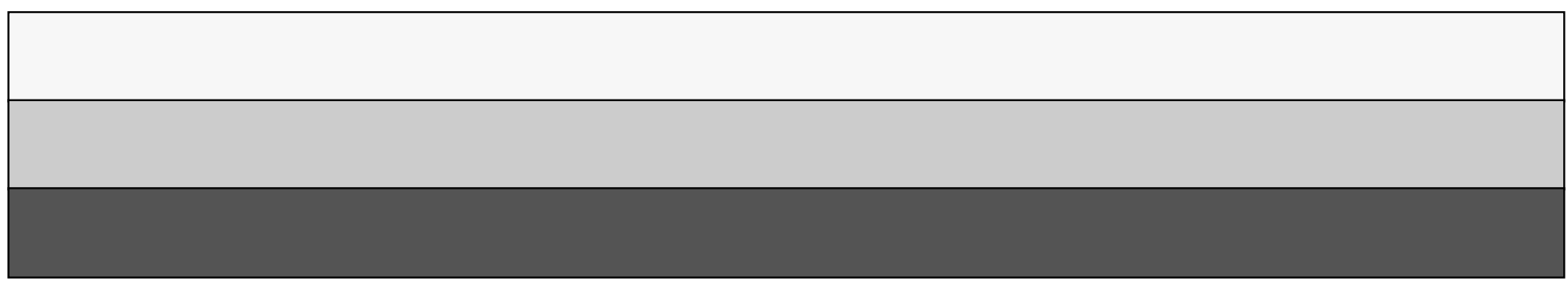

